\title{
A percepção dos professores da rede municipal de ensino sobre a violência nas escolas do município de Cáceres-MT
}

\author{
The perception of teachers from the municipal education system about school \\ violence in the city of Cáceres-MT
}

Marcos Ferreira Medeiros

Mestre em Educação pela Universidade do Estado de Mato Grosso. Policial Militar,Cáceres, MT - Brasil marcosfm007@hotmail.com

Maria do Horto Salles Tiellet

Doutora em Educação. Professora do Programa de Pós-Graduação em Educação da Universidade do Estado de Mato Grosso, Cáceres, MT' - Brasil. mariadohorto_tiellet@yahoo.com.br

Aline Rejane Caxito Braga

Doutora em Psicologia pela Universidade Federal do Rio de Janeiro. Professora da Faculdade do Pantanal. Cáceres, MT - Brasil. aline_caxito@yahoo.com.br

Resumo: Recorte de uma dissertação, neste artigo apresentam-se os resultados da pesquisa desenvolvida com o objetivo de conhecer a percepção dos professores da rede municipal de ensino sobre a violência escolar e a relação desta com a violência urbana. A pesquisa desenvolvida foi descritiva de abordagem quali-quantitativa. As escolas pesquisadas foram selecionadas com base nos registros de homicídios no município de Cáceres/MT, do período de 2010 a 2017. Foram escolhidas quatro escolas localizadas em bairros com o maior número de homicídios, e a amostra foi constituída de quarenta e um sujeitos. As ações tipificadas pelos professores como sendo violência são, em sua maioria, comportamentos de indisciplina e incivilidade. Para os professores, a violência influencia o ambiente escolar, porém, consideram violência urbana aquela oriunda do contexto familiar, e não a relacionaram aos homicídios que ocorreram no bairro em que a escola está localizada.

Palavras-Chave: Violência escolar. Violência urbana. Escolas municipais. Professores.

\begin{abstract}
As part of a dissertation, this article introduces the results of a research made with the objective of learning the perception of teachers from the municipal education system about school violence and its relationship with urban violence. It is a descriptive research with qualitative and quantitative approach. The investigated schools were selected according to records of murders in the municipality of Cáceres, MT, in the period from 2010 to 2017. The selection comprised four schools from the city sections with the higher number of murders and the sampling had forty-one subjects. Actions categorized as violence by the teachers were mostly behaviors of indiscipline and anti-social conduct. From the teachers' point of view, violence does influence the school environment, however they consider that urban violence derives from the family context; thus, they do not relate it to the homicides that occurred in the area where the school is located.
\end{abstract}

Keywords: School violence. Urban violence. Municipal Schools. Teachers. 


\section{Considerações iniciais}

A violência é um fenômeno social que se manifesta de diversas formas e níveis e está presente em todos os contextos sociais, inclusive nas escolas. Nestas, a violência pode ser praticada tanto por atores escolares quanto por estranhos ou até mesmo pela própria instituição. Ao invadir os muros da escola, a violência interfere no cotidiano escolar, nas relações interpessoais entre os atores escolares e no processo ensino aprendizagem, além de provocar sentimentos de medo e insegurança em toda a comunidade escolar, a qual toma, sob forte emoção, medidas nem sempre mais adequadas à situação. Às vezes, a escola envolve agentes de segurança pública, chamados para gerenciar conflitos, no âmbito escolar, que fogem as suas funções.

A violência na escola é um assunto que desperta interesse e tem sido tema de pesquisas em todo o território nacional, por esse motivo buscou-se explorar a temática na cidade de Cáceres, município fronteiriço, uma das portas de entrada do tráfico internacional de armas e de entorpecentes no Brasil. A influência dessas duas mercadorias eleva o índice de violência urbana em qualquer região do país e pode se refletir no cotidiano das escolas.

O crescimento da violência urbana no Brasil pode ser constatado, conforme Adorno (2002), por meio de quatro tendências: a) crimes contra o patrimônio (roubo, extorsão mediante sequestro e crimes contra a pessoa de natureza homicídios); b) criminalidade organizada, especialmente o tráfico de entorpecentes; c) violação dos direitos humanos; d) conflitos nas relações interpessoais. Inclui-se a violência intrafamiliar também conhecida por violência doméstica (MINAYO, 2006). Nesta pesquisa, fez-se um recorte para discutir, no contexto da violência urbana, somente o homicídio.

Para verificar se a violência urbana de Cáceres influencia o ambiente escolar, foram identificados os bairros que possuem maior número de homicídios registrados pela Polícia Militar no período de 2010 a 2017. Posteriormente, escolheu-se um bairro por quadrante da cidade cuja violência urbana, caracterizada pelo homicídio, se manifesta com maior frequência, e nesse bairro foram selecionadas as escolas a serem pesquisadas a fim de conhecer a percepção dos professores sobre a violência escolar e se esta tem relação com a violência urbana.

No contexto escolar, a violência pode ocorrer na relação professor/aluno, resultante de práticas autoritárias e sem espaço para a crítica, para o diálogo; nas práticas disciplinares que buscam a sujeição do aluno — a submissão, a obediência e o 
conformismo. E mesmo em ações de incivilidade: palavrões, ofensas, desrespeito, intolerância, gestos.

A delimitação dos papéis sociais nas relações professor-aluno torna-se um fator importante, todavia é fundamental observar os limites de cada um, as leis que estabelecem direitos e coíbem as transgressões. A opressão pode ser exercida sobre os alunos pela não aplicação da lei, mas também pela sua ausência, quando alguém impõe seu arbítrio e sua vontade (JUSTO, 2003).

\section{A violência e os seus reflexos no cotidiano escolar}

Para Odalia (1983), a violência está presente no cotidiano do homem, deixando de ser um ato circunstancial para se transformar em um modo de ver e de viver o mundo, principalmente nas grandes cidades, onde se encontram as aglomerações humanas. A violência caracteriza-se pela ideia de força contra alguém, que se torna um incômodo ao outro. Para esse autor, quando se fala em violência, a primeira imagem que se revela é a agressão ocasionada pelo modo de produção capitalista. Somado a isso, Odalia (1983) relaciona o conceito de violência às situações de privação, de modo que, toda vez que somos privados de algo, privados dos direitos fundamentais à vida, conquistados a duras penas e reconhecidos pela humanidade, estamos sendo vítimas da violência.

Nesse sentido, uma das formas de violência é a desigualdade social, considerada um dos fatores que acabam gerando conflitos e resultam em violência entre os indivíduos. Para Odalia (1983), as condições de miséria, fome, pobreza, riqueza em uma sociedade capitalista são percebidas como uma ordem natural, e esses tipos de violência aparecem tanto no aspecto político quanto econômico. Contudo, pode-se mencionar, segundo o mesmo autor, que toda violência é estrutural, provocada, em parte, pelo Estado, e é também social, resultante da desigualdade alimentada por um sistema explorador, excludente e injusto.

$\mathrm{Na}$ vida social do homem, a violência é parcialmente desvendada, e por ser assim é manipulada como uma prática de dominação entre os desiguais (ODÁLIA, 1983). No cenário de desigualdade e de exclusão social de um grupo de pessoas, de comunidades e de nações decorrem diversas formas de violência, o que Bauman (2005; 2007; 2009) configura e denomina de modernidade líquida. Para esse autor, a modernidade líquida pode ser entendida como um processo de individualização e privatização do espaço público, relacionado à nova dominação econômica extraterritorial. Para Bauman (2009), no início da 
era industrial as classes contestadoras, especialmente a classe operária, eram percebidas como classes perigosas. A classe operária, na luta contra a exploração e a exclusão social, contra o desprezo racial e cultural, sofre com a violência estrutural, com a violência legitimada pelo Estado opressor e punitivo.

Em contraponto à violência estrutural destacamos a agressividade como originária da natureza humana, que pode resultar em violência — impulso destrutivo (Freud, 2011) —, fruto da inexistência do poder, da negação da palavra (Arendt, 2013), resultante do modelo de produção capitalista — violência estrutural (Odália,1983) —derivada de um modo de vida que esfacela as relações entre os homens, etnias e nações, e liquefaz sentimentos de respeito, tolerância, paciência, segundo Bauman (2009).

A violência como fenômeno não é contemporânea, mas apresenta características e formas nos diferentes contextos sociais. A violência ocorre no ambiente privado por diferentes motivos e atores, e ocorre no ambiente público, nas vias transitáveis, em locais públicos, nos espaços de concentração humana para deslocamento, nas comemorações, nos espaços de diversão e de lazer, e a este último denominamos de violência urbana. Esse fenômeno tem afetado também o contexto escolar.

No contexto escolar, as manifestações podem ser tipificadas como conflito e/ou violência. O conflito, segundo Minayo (2006, p.34), "não é ruim: ele faz parte das relações sociais e humanas". Podemos considerar conflito, na escola, os comportamentos de incivilidade e indisciplina. Nesses casos, é possível “[...] resolver por meio da conversa, da explicitação civilizada de pontos de vista diferentes, da compreensão das razões de cada uma das partes, buscando, pela negociação, uma saída pacífica para os problemas”. (MINAYO, 2006, p. 34).

O grave, segundo Minayo (2006) é a incapacidade de resolver os conflitos pelo diálogo, é transformá-lo em intransigência, exigindo que o outro se cale e se anule pela ameaça e maus-tratos. A violência que pode ocorrer na escola deve ter estreita relação com os dispositivos legais existentes no país e a forma contundente com que a Organização Mundial da Saúde conceituou violência: "uso intencional da força física ou do poder real ou em ameaça, contra si próprio, contra outra pessoa, ou contra um grupo ou uma comunidade, que resulte ou tenha qualquer possibilidade de resultar em lesão, morte, dano psicológico, deficiência de desenvolvimento ou privação". (KRUG et al., 2002, p. 5).

Para Charlot (2002), a violência escolar se manifesta de maneiras distintas: a violência na escola, contra a escola, e da escola. Para esse autor, a violência na escola refere- 
se a todo tipo de violência que se manifesta dentro do espaço escolar - crimes, vandalismo, violência física e sexual, agressões, entre outras. A violência contra a escola está ligada à instituição escolar e envolve depredação do patrimônio e pichações; e a violência da escola refere-se à institucional, ou violência simbólica, caracterizada pelas relações autoritárias estabelecidas e impostas por professores e autoridades escolares gestores e funcionários contra alunos. Essa violência produzida pelos agentes escolares também é denominada violência da escola por Abramovay (2002).

\section{Descrição metodológica}

Esta pesquisa busca desvendar se há relação entre a dita violência escolar e a violência no entorno da escola (violência urbana), a partir da percepção do professor sobre os conflitos que ocorrem na escola e a violência em seu entorno.

Partimos do pressuposto de que a violência, em seus diversos aspectos, está presente em todos os contextos sociais e tem ultrapassado os muros da escola. Os noticiários sobre a violência na escola — originada em seu interior, ou aquela que ocorre no seu entorno - implicam a percepção dos atores escolares, mesmo que a violência que impacta as escolas não ocorra próxima das instituições nas quais os atores se encontram.

E se a sala de aula, compreendida como marcador significativo na escola, que regula as práticas e define os papéis, simbolizada como espaço de aprendizagem (BRAGA, 2010), for invadida por conflitos, sejam eles físico, moral e/ou psicológico, poderá ocorrer instabilidade e insegurança em toda a comunidade escolar. A insegurança, muitas vezes, pode ocorrer devido à falta de informação e de esclarecimento por parte dos atores escolares para distinguirem, por exemplo, um ato de incivilidade, que pode ser hostil e agressivo, e nem por isso violento, da microviolência que não deixa marcas físicas, mas que é classificada como violência. Soma-se a isso o fato de a comunidade escolar não dispor de ações concretas de enfrentamento e prevenção do conflito e da violência em suas escolas, que se embasem em estudos científicos sobre o que de realmente acontece.

Nesse contexto, conforme Tiellet (2012), as ações tipificadas de violência na escola são variadas, incluindo, nesse rol, desde os casos de indisciplina até ações mais graves e delituosas como é o caso de homicídios. Para a autora, "o risco que se corre ao definir uma grade de ações para caracterizar o termo violência na escola é o da banalização ou da naturalização dos atos, além da execução de iniciativas de prevenção desconectadas da realidade". (TIELLET, 2012, p.112). 
De acordo com as características do estudo, a pesquisa desenvolvida foi descritiva de abordagem quali-quantitativa, buscando-se estabelecer relação entre a violência urbana, com recorte sobre o homicídio, e a violência na escola. A pesquisa quali-quantitativa ou método misto, permite cruzar dados numéricos com dados qualitativos. A combinação dessas duas abordagens na pesquisa possibilitou olhares diferentes.

Após a análise quantitativa dos registros de homicídios, por bairro, obtidos através do setor de estatística da Polícia Militar (PM) do município de Cáceres, do período de 2010 a 2017, foi possível selecionar os quatro bairros com maior índice de homicídios, sendo selecionado um bairro em cada um dos quadrantes: Norte, Sul, Leste e Oeste. Os bairros selecionados foram: Centro, Jardim Guanabara, Nova Era e Vila Nova.

Optou-se por desenvolver a pesquisa em escolas da rede municipal de ensino de Cáceres que possui vinte e quatro unidades escolares localizadas na área urbana. Dentre essas, foram escolhidas quatro, localizadas nos bairros que apresentaram maior número de ocorrências de homicídios no período estabelecido. Com esse critério, identificamos, no quadrante Sul da cidade, o bairro Jardim Guanabara, e nele a escola Jatobá; no quadrante Norte, o bairro Vila Nova, onde foi selecionada a escola Pequi; no quadrante Oeste, o bairro Centro, e nele a escola Mangaba; e, por fim, no quadrante Leste, o bairro Nova Era, sendo selecionada a escola Bocaiúva. A partir da escolha das escolas definimos os sujeitos da pesquisa.

O critério de escolha dos sujeitos, prioritariamente, foram os professores efetivos do $1^{\circ}$ ao $9^{\circ}$ ano, incluindo Coordenadores (as), Diretores (as), lotados(as) na instituição há mais de dois anos e que aceitaram participar voluntariamente da pesquisa mediante a assinatura do Termo de Consentimento Livre e Esclarecido

Segundo dados da Secretaria Municipal de Educação (SME), a rede de ensino em Cáceres-MT possui, no quadro docente, duzentos e dez professores efetivos e cento e noventa e sete contratados. A amostra foi constituída de quarenta e um sujeitos, atingindo o percentual de $19,52 \%$ do quadro docente efetivo, e 10,07\% do quadro total de professores da rede municipal de ensino de Cáceres.

Os instrumentos utilizados na pesquisa foram escolhidos conforme a necessidade de investigar o fenômeno da violência dentro e fora das escolas. Assim, para a coleta de dados foram utilizadas fontes documentais e questionário semiestruturado.

\footnotetext{
${ }^{1}$ De acordo com o Parecer n ${ }^{\circ} 2.354 .366$ do Comitê de Ética em Pesquisa da Unemat, datado de 27 de outubro de 2017.
} 
As fontes documentais de natureza pública foram: a base estatística da Polícia Militar referente aos homicídios registrados no ano de 2010 a 2017 que subsidiou a escolha das escolas e o Livro de Ocorrência (LO) das escolas envolvidas na pesquisa, com os quais foi possível identificar os conflitos que aconteceram entre os atores escolares.

Mediante o questionário aplicado aos professores, coordenadores e diretores, buscamos informações a respeito da percepção sobre a violência no espaço escolar, e as ações de prevenção e enfrentamento.

Os dados foram sistematizados e analisados a partir de dois métodos: quantitativo e qualitativo. O quantitativo correspondeu aos dados sobre homicídio na cidade de Cáceres e também o número de professores da rede pública municipal por estabelecimento de ensino. Já as questões abertas do questionário sobre a percepção dos professores foram submetidas à análise qualitativa, tratada através da técnica de Análise de Conteúdo de Bardin (2010), por ser uma técnica utilizada em pesquisas qualitativas e por proporcionar a criação de categorias que permitem a realização de inferências e a compreensão do fenômeno estudado.

\section{Apresentação dos dados: manifestações extramuros e intramuros}

Em sete anos, no período de 2010-2017, ocorreram 83 homicídios na cidade de Cáceres, distribuídos entre os 49 bairros da cidade, sendo os mais afetados: Nova Era, 11; Centro, 8; Cavalhada I, 7 e; JD São Luiz, 5. Os bairros restantes apresentaram número inferior a cinco homicídios.

Nos Livros de Ocorrência (LO) das escolas observamos que a escola registra tudo, incluindo faltas sem justificativas, ou quando o aluno precisa se ausentar por estar passando mal, e também quando o aluno se evade da escola. É o documento no qual as manifestações atípicas, sejam elas correspondentes às atividades didático-pedagógicas ou não, são registradas. Assim, os LO serviram para identificar e tipificar, no ano de 2017, as manifestações que ocorreram no interior das escolas, além de mapear os locais onde as manifestações ocorreram.

Nos registros constam a data do fato, o local, os nomes dos envolvidos, os motivos, o nome do docente que fez o encaminhamento e a ação tomada pela escola. Conforme os registros nos LO, os locais onde mais ocorrem as manifestações de conflitos e de violência são: a sala de aula, fila do lanche, pátio, banheiro, hora do recreio, quadra esportiva, corredores e no entorno da escola. A maior parte dos registros na sala de aula 
refere-se a comportamentos de indisciplina, incivilidades, e em alguns casos a violência física/vias de fato. Para Tsukamoto (2015), a sala de aula é o lugar onde os conflitos acontecem naturalmente, as diferenças e contradições se evidenciam com facilidade pela interação entre os indivíduos.

Segundo Tiellet e Costa (2006), nas escolas públicas de Cáceres são comuns as cenas de indisciplina, incivilidade, conflitos interpessoais, microviolências, brincadeiras, com maior ou menor grau de risco à integridade física de alguém, crimes contra o patrimônio, contravenções e agressividade. Essas manifestações constam nos registros dos LO das escolas pesquisadas, e, para este estudo, foram sistematizadas em duas tipificações: conflitos e violência.

$\mathrm{Na}$ tipificação - conflito - reuniram-se manifestações categorizadas como indisciplina e incivilidade. Tanto nas manifestações de indisciplina quanto nas de incivilidade as medidas adotadas estavam no círculo de medidas didático-pedagógicas, enfim, no âmbito educacional.

A indisciplina se destaca como a mais frequente registrada nos Livros de Ocorrência. Refere-se a comportamentos caracterizados pela zombaria, risadas, pelo sarcasmo, deboche, desacato, atos de comunicação não verbal, incluindo o gesto, o olhar, o não fazer nada, o silêncio, ruídos, mímicas, desobediência e também a indiferença, os quais causam desconforto aos docentes (TIELLET, 2012). Comportamentos estes direcionados especificamente à autoridade educacional (professor, gestor, funcionário), relacionados ao processo didático-pedagógico. (TIELLET; COSTA, 2006).

$\mathrm{Na}$ tipificação conflito também encontramos a incivilidade representada por agressões verbais expressas por palavras inadequadas, xingamentos, apelidos, palavrões, ofensas, deboche, gozação, atos e gestos obscenos, atitudes agressivas, como empurrões, arranhões e jogar material escolar no colega. As medidas tomadas pelas escolas para os conflitos categorizados por indisciplina e incivilidade foram semelhantes: exigir pedidos de desculpas, convocação dos pais e encaminhamento para a secretaria da escola.

Outra manifestação que ocorre nas escolas pesquisadas foi denomina violência, delineada pelas categorias: microviolência, ato infracional e delito, todas com grau leve de gravidade. Nas manifestações tipificadas de violência os agentes de segurança devem ser chamados porque os atos infringem as leis.

Manifestações categorizadas de microviolências foram produzidas por agentes escolares (professor e funcionário) contra alunos, sendo essa mesma ação denominada pelos autores Abramovay (2002) e Charlot (2002) de violência da escola. Nesta, os atores 
educacionais foram protagonistas de ações categorizadas de microviolências contra alunos. Verifica-se que o Conselho Tutelar (CT) não foi convocado para resguardar a criança ou o adolescente. $\mathrm{O}$ docente não prestou esclarecimento do fato ocorrido ao responsável pelo aluno. E pelo fato não foi apresentado a ele advertência A microviolência praticada pelo professor não repercutiu formalmente na Secretaria Municipal de Educação (SME).

Outra manifestação que se enquadrou como violência foi o ato infracional e o delito, ambos relacionados ao dano patrimonial público ou particular. O dano patrimonial é denominado, por Abramovay (2002) e Charlot (2002), de violência contra a escola. Nos Livros de Ocorrências está registrada essa manifestação por ações de alunos e de estranhos. Os atos infracionais praticados pelos alunos que correspondem às depredações do patrimônio público ou privado foram tratados mediante o ressarcimento do dano, convocação dos pais, e Conselho Tutelar e SME informados. Naqueles casos envolvendo ações de estranhos na escola, furto de bicicleta e celular no interior da escola, a polícia foi acionada e foi registrado o Boletim de Ocorrência (BO). Nas ações de violência praticadas por funcionários da escola, do tipo ameaças, prevaricação, agressão físicas, foram registrados Boletins de Ocorrência, mas a polícia não foi chamada.

Nos LO foi possível constatar que a polícia foi acionada nos casos de delitos praticados por estranhos no recinto escolar, enquanto que casos de violência praticada por dirigentes educacionais (microviolência) isso não aconteceu e muito menos o caso chegou formalmente à SME. Todavia, em relação às ações do aluno contra o professor, a polícia militar foi acionada pela direção da escola, para proteger o professor, para controlar a situação e registrar BO contra o aluno. Nesse sentido, comparando as medidas de enfrentamento das ações tipificadas nas escolas como violência, foi possível constatar que a atuação da escola frente à violência no seu contexto depende de quem é o agressor.

Constatamos também, através dos registros nos LO, que algumas manifestações se repetem nas quatro escolas, porém, as medidas tomadas por elas são diferentes. Além disso, na mesma escola as ações tomadas em resposta aos eventos ocorridos se diferenciam em relação a manifestações semelhantes.

Embora a cidade de Cáceres, município fronteiriço, seja uma das portas de entrada do tráfico internacional de armas e de entorpecentes no Brasil, e, segundo estudos, a influência dessas duas mercadorias eleva o índice de violência que pode se refletir no cotidiano das escolas, não houve registro, nos Livros de Ocorrência, sobre questões referentes ao tráfico ou ao uso de droga no interior e no entorno das escolas pesquisadas. 
Apresentação dos dados: o ambiente escolar e a percepção do professor sobre a violência na escola

O questionário semiestruturado, aplicado aos professores das escolas Jatobá, Pequi, Mangaba e Bocaiúva, foi constituído de campos distintos a fim de conhecer a percepção do professor (a) a respeito da violência no ambiente escolar.

Em relação à percepção dos professores sobre o ambiente da escola, a maioria dos sujeitos pesquisados o considera muito bom e razoável, destacando-se a Escola Mangaba no quadrante Oeste cujo ambiente foi considerado muito bom pelo conjunto dos docentes pesquisados. Já os docentes da Escola Jatobá, localizada no quadrante Sul, classificaram o ambiente como regular. Apenas dois professores de duas escolas (Bocaiuva e Jatobá) disseram que o ambiente das mesmas era ruim.

Na Escola Jatobá e na Escola Mangaba alguns professores não se sentem seguros no seu interior, embora a maioria dos professores pesquisados tenha respondido que se sentem seguros na escola em que trabalham.

Questionados se se sentem ameaçados, quarenta professores disseram que não. Somente na Escola Jatobá, quadrante Sul, houve caso de ameaça contra um professor por alunos e pais. Os professores da Escola Mangaba, quadrante Oeste, bairro Centro, o segundo bairro em número de homicídios, afirmam que seus alunos não são violentos. Os professores das Escolas Pequi, Bocaiuva e Jatobá não foram conclusivos em relação à percepção sobre seus alunos. A maioria dos professores pesquisados respondeu que não avalia seus alunos como violentos, enquanto outro conjunto de professores afirma o contrário, pois considerou seus alunos um "pouco" violentos.

Assim, apesar de poucos professores afirmarem não se sentir seguros no interior da escola, considerarem o ambiente ruim por terem sofrido ameaças de seus alunos e estes serem considerados um pouco violentos, todos os professores pesquisados manifestaram que querem permanecer trabalhando nessas escolas. Isso suscita os seguintes questionamentos: Por que não mudariam de escola? Por que continuar trabalhando em um ambiente que consideram ruim e violento?

Quanto à categoria percepção dos informantes sobre o entorno da escola, as respostas pouco violento e violento superam numericamente os que afirmam ser tranquilo o entorno da escola. Destacamos o conjunto dos professores da Escola Jatobá, em que apenas dois deles afirmaram não ser violento o entorno da escola. Nenhum dos sujeitos das quatro escolas pesquisadas indicou o quesito "muito violento" para o entorno, o que nos leva a concluir 
que os professores não consideram a localização da escola um fator de risco, embora todas elas estejam localizadas em bairros com o maior número de homicídios na cidade.

Professores da Escola Jatobá, quadrante Sul, foram os únicos, por unanimidade, que propuseram a colocação de grades, cadeados, muros para, provavelmente, conter a violência do entorno que adentra na escola. A Escola Mangaba foi a única escola que não indicou a suspensão ou transferência de escola como punição para os alunos indisciplinados. A Escola Bocaiuva não indicou a necessidade de reformas (iluminação, pintura, reparo nas janelas, com a colocação de vidros), por certo não é a estrutura da escola que incomoda e inquieta os professores. A totalidade dos professores da Escola Jatobá e da Escola Pequi entende que todas as ações apresentadas devem ser implantadas para que a escola seja um lugar seguro.

O conjunto dos professores pesquisados destaca a necessidade de capacitação dos professores para lidar com a violência, e, na sequência, indicam que se faz necessária maior vigilância, incluindo policiamento no entorno, vigias e inspetores de corredor, constatandose que as inquietações dos professores, os conflitos e a violência são específicas de cada escola,pois o ambiente escolar é permeado por significações, valores, ideologias, que cada indivíduo carrega e são compartilhados, aprendidos e internalizados na relação com o outro.

\section{Considerações Finais}

Nesta pesquisa buscamos conhecer a percepção dos professores das escolas da rede municipal de Cáceres/MT, localizadas nos bairros com maiores registros de homicídios.

Constatamos que as ações registradas nos Livros de Ocorrências pelos professores são, em sua maioria, relativas a comportamentos de indisciplina e incivilidades, já apontadas por Tiellet (2012) e Tsukamoto (2015).

A violência está categorizada, nessa pesquisa, pelos atos de microviolências, por delitos (crime, propriamente dito) e pelo ato infracional, e constatamos, nos Livros de Ocorrências, que não há menção à chamada policial para atender essas manifestações de violência produzidas por diferentes atores (professor e funcionários) em diferentes ocasiões. Embora para o professor pesquisado tudo o que ocorre na escola é violência pois, assim nomeia a indisciplina e a incivilidade, constatamos que há uma incoerência aparente entre a percepção dos professores sobre violência e a atitude concreta tomada pela escola para 
enfrentá-la, dado que a PM não é chamada pelos gestores a intervir em casos concretos e objetivos de violência.

Em todas as escolas os sujeitos pesquisados apontaram a necessidade de maior vigilância, tanto interna quanto externamente, com a presença da polícia militar. Também manifestaram a necessidade de treinamento e formação de professores para lidar com o fenômeno da violência e foram unanimes em abrir a escola em horários alternativos para a comunidade local realizar atividades.

Na percepção da maioria dos professores, a violência urbana pode ultrapassar os muros, porém, as influências apontadas pelos professores ocorrem devido aos problemas existentes na comunidade, entre vizinhos, e questões intrafamiliares que saltam os muros da escola e influenciam o ambiente escolar, prejudicando a aprendizagem e ampliando o sentimento de insegurança dos professores.

Para os professores, os alunos reproduzem o que veem. Assim, ao presenciarem situações de violência na família acabam reproduzindo esses comportamentos na escola, e também expressam através de revolta, de indisciplina e de violência o sofrimento que vivenciam. Os comportamentos aprendidos e internalizados no meio social são expressos nos diversos contextos e relações do indivíduo, o que se estende ao ambiente escolar. Mesmo tendo os professores essa percepção, nenhuma das escolas possui estratégias de enfrentamento e de prevenção dos conflitos e da violência elaborada para atender as especificidades do que ocorre em seu interior ou entorno, e quando há são ações propostas pela PM - Ronda, Rede Cidadã e Proerd -, que, embora importante, não são o suficiente para responder ao conjunto das manifestações que ocorrem no estabelecimento de ensino.

A percepção dos professores é de que a violência urbana, a violência do entorno da escola, tem sua origem nas relações interpessoais e intrafamiliar. Não está na memória dos professores o número de homicídios que concretamente ocorreu no bairro, às vezes em intervalo de tempo longo, e, sim, as violências interpessoais e domésticas que estão no cotidiano da comunidade do entorno e no sofrimento diário dos alunos das escolas pesquisadas.

Os dados obtidos através da pesquisa apontam que o município de Cáceres é constituído formalmente de quarenta e nove bairros, e que, no período de 2010-2017, neles ocorreram oitenta e seis homicídios, o que representa, aproximadamente, dois homicídios por bairro no período de sete anos. Foi possível identificar os bairros com maior número de assassinatos, além dos quatro onde as escolas pesquisadas se localizam: Vila Nova, 4; Centro, 8; Nova Era, 11; Cavalhada I,7; Rodeio, 5; e São Luís, 5. Os bairros com número 
maior de homicídios se localizam nos quadrantes Oeste e Sul. Há queixa dos professores das escolas pesquisadas, nesses quadrantes, sobre a dificuldade de a PM atender algumas chamadas e até mesmo a realização de rondas, seja no entorno da escola ou no bairro. Para um conjunto de professores, quando ocorre o patrulhamento, este é esporádico a ponto de a polícia militar não ser visível.

A totalidade das escolas utiliza ações punitivas depois do fato ocorrido e não ações pedagógicas preventivas. Tais procedimentos punitivos não contribuem para diminuir os conflitos e a violência nas escolas. Além disso, não há, por parte da escola, movimento no sentido de compreender, tipificar as ações que ocorrem para então discutir e elaborar estratégias de redução e prevenção dos conflitos e da violência, incluindo, nesse processo, todos os atores escolares e profissionais da SME, do CT e da PM.

O ambiente escolar como lugar de aprendizagem é também considerado um espaço de conflitos, onde se manifestam, por parte dos atores escolares (professores, funcionários e alunos), comportamentos e atitudes que podem desencadear atos de violência, por não terem, por parte da gestão, a devida atenção e tratamento adequado. Nesse contexto, deduz-se o motivo pelo qual os professores não têm compreendido os diferentes comportamentos no contexto escolar.

As estratégias de enfrentamento dos conflitos e da violência nas escolas devem ser pensadas a partir da percepção das pessoas que estão envolvidas, os atores escolares, a comunidade, para que possam elaborar propostas coerentes com a realidade. Ainda são necessárias formações promovidas pela SME voltadas para essa temática.

Os dados desta pesquisa indicam a necessidade de investigar mais profundamente alguns aspectos, especialmente o fato dos gestores das escolas pesquisadas, localizadas em bairros com número expressivo de violência urbana (homicídio), não solicitarem, com maior frequência, que a PM atenda eventos objetivos, reais, concretos e tipificados, com base na lei, como violência, que eventualmente ocorram na escola ou em seu entorno e mesmo para realizarem ronda preventiva.

E, finalmente, a não menção dos professores ao tráfico de drogas no bairro. Também não houve registros nos Livros de Ocorrência sobre esse delito. Somente o relato de uma caixa de fósforos encontrada na mochila de um aluno, o que pode ou não ter relação com o uso de droga e não com o tráfico de drogas. Isso nos chama a atenção porque a cidade é uma das principais entradas de drogas do Mato Grosso e também do país. 
Tanto o tráfico quanto o uso de drogas no interior ou no entorno foi um assunto silenciado, e pode-se deduzir que, nas escolas pesquisadas, não há esse tipo de ocorrência devido à faixa etária dos seus alunos, ou também pode estar relacionado a algum tipo de omissão ou medo, por serem esses bairros os mais violentos da cidade, por desconhecimento sobre o assunto por parte dos professores ou pela naturalização do fato.

\section{Referências}

ARENDT, Hannah. Sobre a violência. 4 ed. Rio de Janeiro, Civilização Brasileira, 2013. ISBN 978-85-200-0789-1

ABRAMOVAY, Miriam; RUA, Maria das Graças (Org.). Violência nas escolas. Brasília: Unesco, Instituto Ayrton Senna, UNAIDS, Banco Mundial, USAID, Fundação Ford, CONSED, UNDIME, 2002. ISBN 85-87853-47-3

BARDIN, Laurence. Análise de Conteúdo. Portugal, Lisboa: Edições 70, 2010. ISBN 978972-44-1506-2

BAUMAN, Zygmunt. Confiança e medo na cidade. Rio de Janeiro: Jorge Zahar Ed.,2009. ISBN 978-85-378-0122-2

BAUMAN, Zygmunt. Identidade. Rio de Janeiro: J. Zahar, 2005. ISBN 85-7110-889-7

BAUMAN, Zygmunt. Tempos líquidos. Rio de Janeiro: J. Zahar, 2007. ISBN 978-85-7110993-3

BRAGA, A. R. C. Dentro e fora da sala de aula: um estudo acerca das representações sociais dos licenciandos de Pedagogia da UFMT. 184 f. Dissertação (Mestrado em Educação), Universidade Federal de Mato Grosso, Cuiabá, 2010.

CHARLOT, Bernard. A violência na escola: como os sociólogos franceses abordam essa questão. Sociologias. Porto Alegre, no 8, p.432-443, jul./dez. 2002.

FREUD, S. O mal-estar na civilização. São Paulo: Penguin Classics Companhia das Letras, 2011. ISBN 85-312-0575-1

JUSTO, José Sterza. A Psicanálise Lacaniana e a Educação. In: CARRARA, Kester. (Org.). Introdução à psicologia da educação. São Paulo: Avercamp, 2003. p.72-107. ISBN 978-85-8931$113-7$

KRUG, E. G. et al. (Org.). Relatório mundial sobre violência e saúde. Geneva: Organização Mundial da Saúde, 2002. ISBN 92- 4-154561-5

MINAYO, Maria Cecília de Souza. Violência e saúde. Rio de Janeiro: Editora Fiocruz; 2006. ISBN 85-7541-071-7

ODALIA, Nilo. O que é a violência. Coleção Primeiros Passos. 4 ed. São Paulo: Editora Brasiliense,1983. ISBN 85-11-01085-8 
TIELLET, Maria do Horto Salles. As Políticas públicas de redução e prevenção dos conflitos e da violência em ambiente escolar no estado do Mato Grosso, no período de 2003-2010, e os reflexos nas escolas estaduais do município de Cáceres. 2012. 362p. Tese (Doutorado em Educação). Pósgraduação em Educação da Universidade do Vale do Rio dos Sinos. 2012.

TIELLET, Maria do Horto Salles; COSTA, José Ferreira. Brincadeiras que humilham: manifestações de incivilidade. Relatório. 216f. Universidade do Estado de Mato Grosso, Cáceres, MT. 2006.

TSUKAMOTO, Frádia Cícera de Castro. A violência escolar na perspectiva dos professores do ensino fundamental de escolas públicas municipais de Cáceres-MT. 2012.100f. Dissertação (Mestrado em Educação). Pós-graduação em Educação da Universidade do Estado de Mato Grosso. 2015.

Recebido em: 20 mar. 2019 / Aprovado em: 25 jun. 2019

\section{$\underline{\text { Cite como }}$}

MEDEIROS, Marcos Ferreira; TIELLET, Maria do Horto Salles; BRAGA, Aline Rejane Caxito. A percepção dos professores da rede municipal de ensino sobre a violência nas escolas do município de Cáceres-MT. Dialogia, São Paulo, n. 32, p. 10-24, maio/ago. 2019. Disponível em: https://doi.org/10.5585/Dialogia.n32.13309. 